\title{
Serratus plane combined with PECS 1 block is easy to perform and efficient regional anaesthesia method for patient undergoing mastectomy
}

Michal But MD, EDAIC (1) ; Adam Kruczkowski MD (1); Paweł Moszczyński MD (1); Agnieszka Małek MD (1), Mariusz Zieliński MD (1) Jacek Zieliński MD, PhD (2) 1-Department of Anaesthesiology and Intensive Regional Hospital Koszalin , 2-Department of Surgical Oncology, Medical University of Gdansk, Poland

\section{BACKGROUND}

PECS block (1) and serratus plane (SP) block described by Blanco and colleagues (2) are popular fascial plane blocks for breast cancer surgery and an alternative for paravertebral block (PVB), intercostal block, thoracic epidural analgesia. The PECS block target pectoral nerves in fascia between pectoralis major and minor muscles close to the pectoral branch of the thoraco-acromial artery (1) and serratus plane block targets the lateral cutaneous branches of the intercostal nerves. All branches traverse either of 2 fascial planes: superficial to the serratus muscle or deep to the serratus muscles.

\section{METHOD}

The study was designed as prospective, clinical trial. Authors have tested a hypothesis that a good analgesia within the thoracic and axillary region gives administration of a local anaesthetic in the fascia between the serratus and intercostal muscle at the level of the fifth rib in posteriori axillary line. Authors performed 22 deep SP blocks combined with PECS 1 blocks in patients ASA 1-3 qualified to mastectomy with axillary lymphadenectomy in general anaesthesia. Primary and secondary endpoints

-Time of execution of blockade

-requirements for fentanyl during the operation

-pain intensity-Numeral Rating Scale (NRS) when admitted to the wake-up room, 4, 8, 12, 16, 20 and 24 hours after the operation.

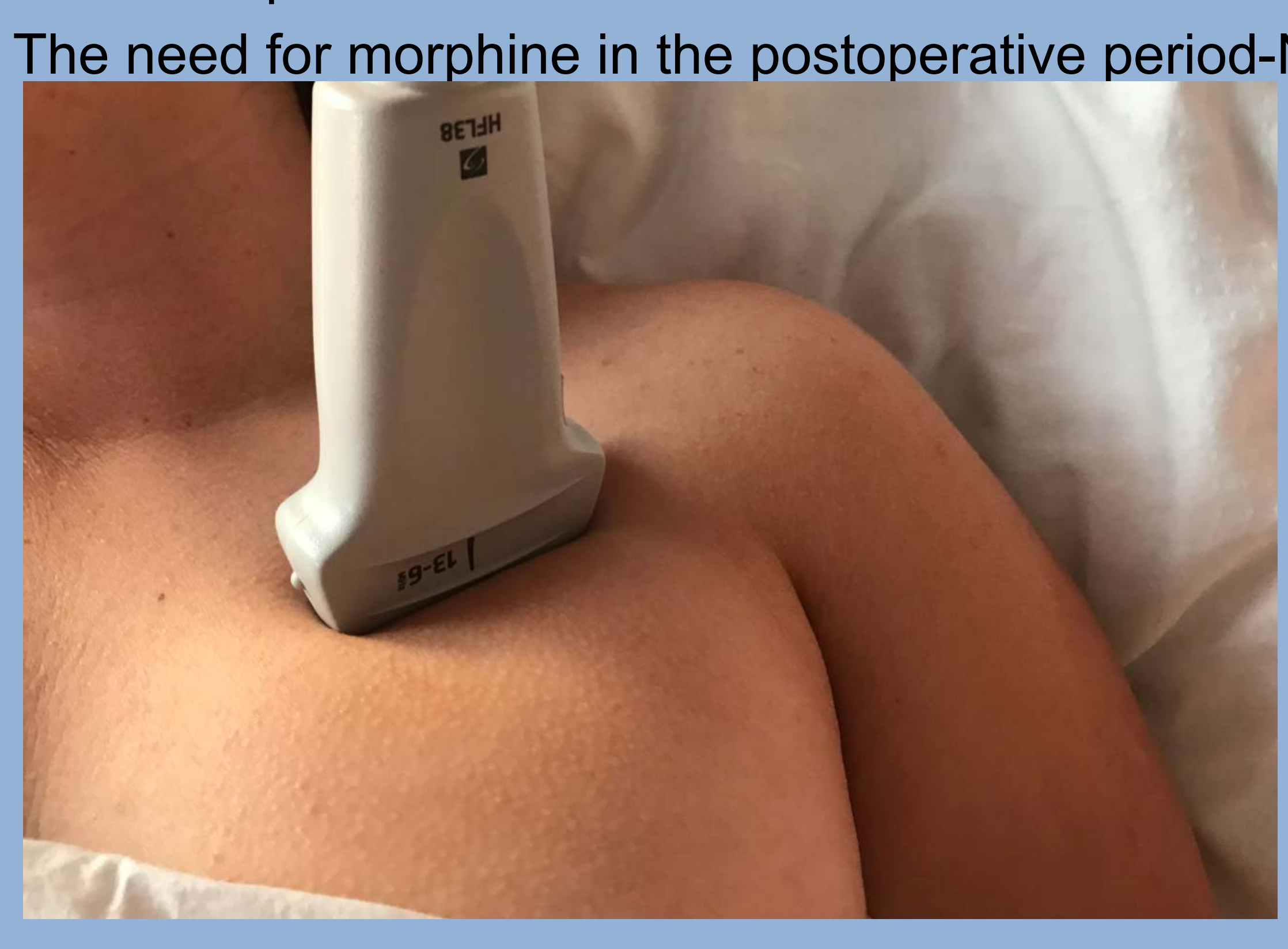

Pic1: position of the probe on the patient- PECS block

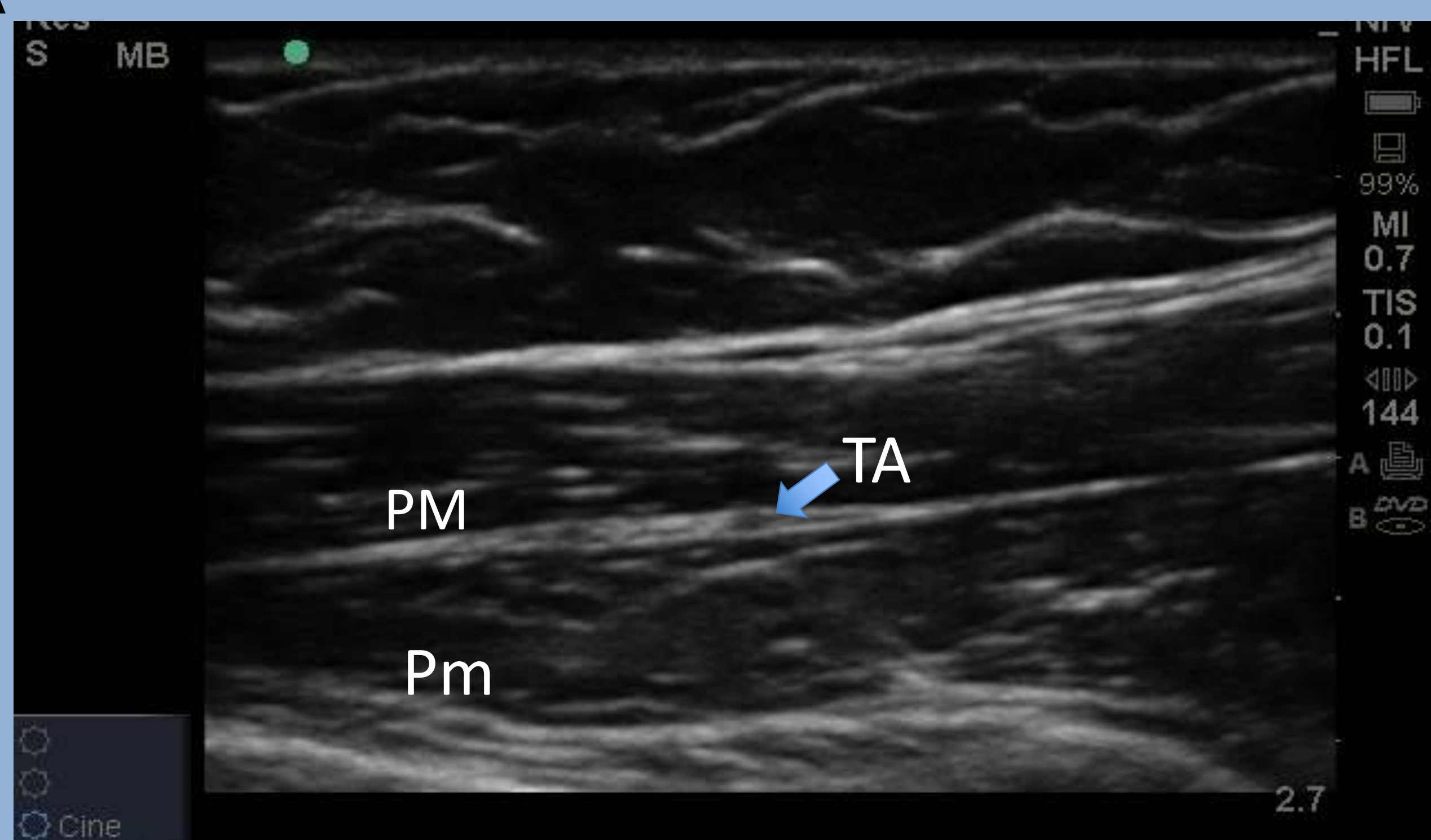

Pic2: PM- pectoralis major muscle; Pm- pectoralis minor muscle; TAthoracoacromial artery

\section{RESULTS}

Average age of patient was 62.3 years. BMI 26. All patients was female.

Time of execution of combined blockade was average $4 \mathrm{~min} 30 \mathrm{sec}$

There was no need of fentanyl administration during operation except of induction to the general anaesthesia

Pain intensity NRS was on average when admitted to the wake up room and 4,8,12,16,20,24 hour after operation respectively $2 ; 2,2 ; 3,2 ; 3 ; 2,8 ; 2,4 ; 2,2$

In postoperative period all patients received Metamizol $1 \mathrm{~g}$ every 6 hours iv. And 6 patients reported pain NRS > 3 at rest or NRS $>4$ in movement and they received Morphine iv in $2 \mathrm{mg}$ boluses. Average amount of morphine given to this patients was $6 \mathrm{mg}$. 16 patients reported NRS $<3$ in postoperative period. There was no adverse effects in postoperative period

\section{CONCLUSION}

Combined PESC 1 and serrato intercostal plane block is easy to perform and effective regional anaesthesia method for patients undergoing mastectomy with axillary lymphadenectomy.

References
1-Blanco R. The PESC block': a novel technique for providing analgesia after breast surgery. Anaesthesia. 2011;66:847-848.

2-Blanco R, Parras T, MCDonnell JG, Prats-Galino A. Serratus plane block: a novel ultrasound-guided thoracic wall nerve block. Anaesthesia. 2013;68:1107-1113

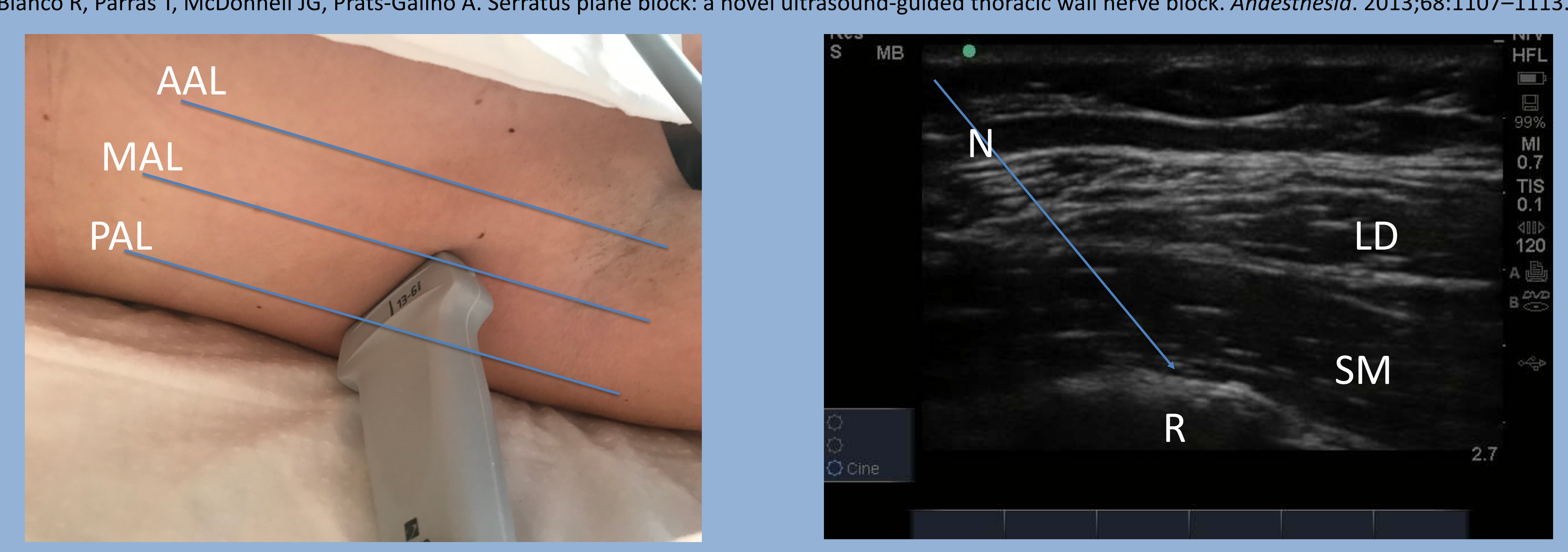

Pic3: position of the probe on the patient - deep serratus plane block AAL-anterior axillary line, MAL- middle axillary line, PAL- posterior axillary line
Pic4: LD-latissimus dorsi muscle; SM- serratus muscle; R- rib, $\mathrm{N}$ - needle 